\title{
Pengambilan Keputusan Menggunakan Analytical Hierarchy Process (AHP) pada Pemilihan Pemasok Produk Lampu
}

\author{
Riska Mulia Arum ${ }^{1}$, Trisna Yuniarti ${ }^{1}$ \\ ${ }^{I}$ Politeknik APP Jakarta, Jalan Timbul No.34, Jakarta Selatan, 12630, Indonesia
}

\section{ARTICLE INFORMATION}

Received: November 19, 2021

Revised: December 15, 2021

Available online: December 31, 2021

\section{KEYWORDS}

AHP, Attribute, Criteria, MCDM, Supplier

\section{CORRESPONDENCE}

Name: Trisna Yuniarti

E-mail: trisna.yuniarti@poltekapp.ac.id

\section{A B S T R A C T}

\begin{abstract}
This study aims to determine the best supplier for in-Lite lighting products. The company chose criteria and sub-criteria in supplier selection to optimize product sales continuity. This study used the Analytical Hierarchy Process (AHP) method, which provided information about the criteria, sub-criteria, and alternatives in the selection of three suppliers: A, B, and C. The existence of priority weights provided a decision in choosing the supplier of the lighting product. The new criteria and sub-criteria were the results of the literature study formulation and then adjusted again with the results of the interview. Seven criteria were determined in this study: production, price, quality, site selection, product suitability, delivery, and service. The results of the calculation of the priority weights of the criteria, sub-criteria, and alternative selection using a questionnaire. The parties involved in the selection of suppliers filled out the questionnaire to obtain a weight for each supplier. Based on the results of AHP calculations, supplier A got the highest weight of 0,442 or $44 \%$, so this supplier is used as a company priority in choosing suppliers for in-Lite type lighting products.
\end{abstract}

\section{PENDAHULUAN}

Era pasar yang kompetitif membuat perusahaan semakin sadar akan pentingnya memilih pemasok yang tepat untuk memenuhi kebutuhan perusahaan. Pada rangkaian bisnis proses suatu perusahaan, pemasok memiliki peranan penting yang bertugas sebagai pemasok pengadaan bahan baku maupun jasa. Berkaitan dengan pemilihan pemasok, pertimbangan yang dianggap penting adalah pemasok yang telah memenuhi syarat, yaitu dapat memberikan kualitas layanan atau produk yang tepat dengan kuantitas, waktu, dan lokasi yang benar kepada produsen. Secara umum, pemilihan pemasok merupakan prosedur pengambilan keputusan multikriteria yang mencakup berbagai macam kriteria, baik secara kualitatif maupun kuantitatif yang diselesaikan sesuai dengan persyaratan pabrikan dan berbeda menurut situasinya [1]. Oleh karena itu, pemilihan pemasok sangat penting dan harus dilakukan dengan tepat guna mendukung kinerja organisasi serta rantai pasok pada kegiatan bisnis suatu perusahaan.
Pada dasarnya, memilih pemasok yang tepat dan mampu memenuhi kebutuhan perusahaan tidaklah mudah, karena perlu pertimbangan yang jelas dan harus diperhatikan agar tidak terjadi kesalahan dalam pemilihannya. Pemilihan pemasok dapat menjadi kegiatan strategis, terutama jika pemasok menyediakan barang-barang penting atau digunakan untuk waktu yang lama [2]. Pemilihan pemasok yang tidak tepat dapat mengakibatkan lead time yang lama, terjadinya hambatan dalam memenuhi kebutuhan pelanggan, dan adanya kerugian bagi perusahaan jika kualitas produk yang ditawarkan pemasok tidak memenuhi persyaratan penjualan sehingga tidak memenuhi permintaan pelanggan. Oleh karena itu, memilih pemasok yang tepat dapat menghasilkan penghematan yang signifikan dan meminimalkan risiko yang timbul. Banyak para ahli menganggap pemilihan pemasok sebagai aktivitas terpenting dari departemen pembelian [3]. Maka dari itu, pemilihan pemasok harus teliti agar dapat memenuhi kriteria yang dibutuhkan perusahaan. 
PT X merupakan perusahaan prinsipal alat penerangan yang memiliki beberapa merek dagang, yaitu in-Lite dan Intech yang diimpor dari China. Selain itu, perusahaan juga menjadi distributor beberapa alat penerang merek lainnya, seperti Ossio, Osram dan Akon. Perusahaan ini memiliki produk utama, yaitu produk in-Lite, seperti yang terdapat pada Tabel 1. Produk in-Lite merupakan merek dagang yang diminati oleh banyak konsumen, terutama pada jenis lampu Bulb Series.

Pada bulan Maret - April 2021 didapatkan informasi bahwa jumlah kontainer yang melakukan bongkar muat barang pada gudang Jababeka sebanyak 43 container dengan kapasitas 40 fit. Volume pengadaan barang untuk produk in-Lite dapat mencapai \pm 100 container yang datang dari gudang pusat di Jababeka per tahunnya. Dari $100 \%$ hasil penjualan perusahaan tersebut, 55\% merupakan hasil penjualan produk jenis in-Lite. Hal ini bisa dikatakan produk ini merupakan produk yang dapat mendatangkan keuntungan lebih tinggi bagi perusahaan.

Tabel 1. Jenis Produk in-Lite

\begin{tabular}{cc}
\hline No. & Jenis Lampu \\
\hline 1. & Bulb Light \\
2. & Panel Light \\
3. & Food Light \\
4. & Fixture \& ACC \\
5. & Downlight \\
6. & Tube Light \\
7. & Street Light \\
8. & Ceiling Light \\
9. & Wall Light \\
10. & Highbay \\
11. & Driver \\
12. & Flexi Strip \\
13. & Track Light \\
14. & Reading Lamp \\
15. & Head Lamp \\
16. & Spotlight \\
\hline
\end{tabular}

(Sumber: PT X)

Pada tahap awal pemilihan pemasok, PT X melakukan kunjungan langsung ke China untuk melakukan pemilihan pemasok yang dibutuhkan. Namun pada masa pandemi Covid-19, perusahaan melakukan pemilihan pemasok berdasarkan penawaran yang berdasarkan dua kriteria, yaitu kualitas (teknologi) yang digunakan oleh pemasok dan dari segi harga (cara pembayaran/tempo pembayaran). Pemilihan pemasok yang dilakukan oleh perusahaan dirasa kurang maksimal karena perusahaan hanya memilih pemasok berdasarkan dua hal tersebut menyebabkan adanya keluhan di gudang pusat (Jababeka) maupun pada kantor pusat. Hasil wawancara diketahui bahwa selama periode 2017 hingga saat ini terdapat beberapa keluhan yang pernah dialami oleh perusahaan, seperti: kekurangan kuantitas barang yang datang, barang tidak sesuai dengan permintaan (barang cacat), kesalahan kode item barang dan keterlambatan pada pengiriman barang dari pemasok. Hal ini mengakibatkan perusahaan terhambat dalam melakukan penjualan yang akhirnya mempengaruhi kontinuitas penjualan produk pada perusahaan. Pada periode tersebut perusahaan telah mengalami pergantian pemasok sebanyak tiga kali. Dari ketiga pemasok tersebut dirasa masih belum optimal dalam memberikan produk dengan kualitas, kuantitas dan pengiriman produk yang diinginkan perusahaan yang akhirnya berdampak pada kontinuitas penjualan produk dikarenakan pemilihan pemasok hanya berdasarkan dua kriteria saja. Oleh karena itu, perusahaan mengkaji kembali kriteria-kriteria lain untuk mengatasi masalah-masalah yang muncul di perusahaan untuk menunjang kelangsungan penjualan, termasuk memilih pemasok yang tepat berdasarkan kriteria yang sangat dibutuhkan perusahaan.

Tujuan studi ini adalah untuk mendapatkan keputusan dalam memilih pemasok yang tepat berdasarkan hasil kriteria dan sub kriteria serta atribut yang sesuai dengan kebutuhan perusahaan. Pemilihan supplier menjadi suatu masalah dalam mengambil keputusan multikriteria dan hal ini sangat bergantung pada visi pembuat keputusan serta menjadi isu utama diantara manajer rantai pasok [4]. Keputusan tersebut dapat diambil berdasarkan hasil evaluasi pemasok dengan menggunakan kriteria kualitatif maupun kuantitatif untuk mendapatkan pemasok baru atau disesuaikan dengan kasus yang ada.

Teknik Multiple Criteria Decision Making (MCDM) banyak digunakan untuk mengevaluasi, menilai, dan memberi peringkat solusi alternatif terbaik dengan banyaknya kriteria di berbagai industri. Pendekatan pengambilan keputusan MCDM dirancang untuk membantu pengambil keputusan dalam memilih sejumlah alternatif yang terbatas atau menentukan peringkat dan mengurutkan sejumlah alternatif berdasarkan beberapa kriteria. Ada beberapa teknik MCDM yang dapat digunakan, seperti ELECTRE, VIKOR, PROMETHEE, WSM, MAUT, ANP, TODIM, MULTIMOORA, AHP dan TOPSIS [5]. Selain itu, terdapat beberapa teknik dalam mengambil keputusan dengan cara mengintegrasikan beberapa metode. Metode SWARA II, MEREC, WASPAS, Simulasi Monte Carlo, dan model penugasan diintegrasikan dalam menentukan pengambilan keputusan untuk menilai lokasi pusat distribusi [6]. Kombinasi Best Worst Method (BWM) dan Preference Ranking Organization Method for Enrichment of Evaluations (PROMETHEE) untuk menentukan evaluasi pemasok yang berkelanjutan [7]. Dari beberapa metode di atas, salah satu teknik yang dapat diaplikasikan dalam penelitian pemilihan pemasok, 
yaitu metode Analytical Hierarchy Process (AHP). AHP adalah pendekatan yang efektif untuk menangani Multi Criteria Decision Problem (MCDM) dengan cara melakukan pembobotan pada setiap kriteria.

Beberapa penelitian telah menggunakan metode AHP untuk mengambil keputusan multikriteria. Beberapa kasus yang berkaitan dengan pemilihan keputusan yang dengan permasalahan energi telah menggunakan metode ini $[8,9,10,11]$ Pemilihan pemasok listrik rumah tangga di Polandia menerapkan AHP untuk memilih empat pemasok energi listrik, yaitu: Enea, RWE Polska, Ernega, dan PGE. Empat kriteria yang menjadi pertimbangan adalah tarif listrik penghangat rumah; tarif listrik siang dan malam; jumlah energi terbarukan; dan pangsa pasar. Hasil studi menunjukkan bahwa Enea terpilih sebagai pemasok energi listrik rumah tangga dengan bobot sebesar 0,596 [12]. Studi lainnya menggunakan AHP dalam pemilihan keputusan yang berkaitan dengan pemeliharaan di berbagai Industri [8, $9,12,13,14,15]$. Salah satunya dilakukan oleh Industri pupuk kimia di Jordan untuk memilih strategi pemeliharaan yang terdiri dari empat tipe (MS-I s.d. MSIV). Hal pertama yang dilakukan, yaitu dengan mengidentifikasi kriteria dan subkriteria yang berkaitan dengan praktik pemeliharaan yang didapatkan dari tinjauan penelitian dan konsultasi ahli. Hasil menggunakan AHP didapatkan MS-III terpilih sebagai strategi pemeliharan pada industri kimia tersebut dengan total persentase rata-rata sebesar 50,5\% [13]. Begitu juga dengan penggunaan AHP pada penelitian lain yang berkaitan dengan permasalahan pemilihan pemasok telah dilakukan pada beberapa perusahaan guna mendapatkan pemasok sesuai dengan kriteria yang ditetapkan dan sesuai dengan kebutuhan perusahaan $[2,8,12,16]$.

\section{METODOLOGI}

Pemilihan pemasok produk lampu jenis in-Lite menerapkan teknik Analytical Hierarchy Process (AHP) dilakukan dengan beberapa tahapan proses. Teknik ini digunakan untuk memecahkan masalah pengambilan keputusan multikriteria dengan membuat pilihan terbaik dari berbagai pilihan yang ditawarkan. Tahapan proses terdiri dari identifikasi masalah, pengumpulan data, pengolahan data. Hasil pengolahan data tersebut akan dilakukan analisis serta ditarik kesimpulannya.

\section{Identifikasi Masalah}

Tahapan awal pada studi ini adalah melakukan identifikasi masalah. Proses identifikasi masalah dilakukan dengan melakukan observasi di lapangan dan melakukan wawancara dengan Product Development Manager dan Sales Support Asst Manager yang berkaitan dengan pemasok. Identifikasi masalah dimulai dari observasi pada dua gudang pusat. Observasi pertama dilakukan pada gudang pusat yang berada di Jababeka dengan cara melakukan pengamatan pada rangkaian proses bongkar muat barang dari pemasok dan melakukan wawancara terhadap admin gudang tersebut. Observasi kedua dilakukan pada gudang pusat 11 cabang yang berada di Cakung. Observasi tersebut dilakukan dengan cara mengamati rangkaian proses pengiriman barang ke konsumen (retailer), mengamati bongkar muat barang, dan melakukan wawancara dengan kepala gudang. Hasil observasi dan wawancara tersebut ditemukan ada kendala dalam proses pengiriman barang dari gudang ke cabang-cabang hingga ke konsumen perusahaan. Kendala seperti keterhambatan dalam proses penjualan produk perusahaan terjadi karena adanya barang yang tidak tersedia di gudang perusahaan dan adanya ketidaksesuaian barang dengan kemasannya sehingga terjadi hambatan dalam proses pengiriman dan penjualan produk PT X.

\section{Pengumpulan Data}

Teknik pengumpulan data dilakukan dengan menggunakan data primer dan data sekunder. Data primer dilakukan dengan melakukan observasi, wawancara, dan menyebarkan kuesioner. Kegiatan observasi dilakukan dengan mengamati secara langsung ke kantor pusat yang berada di Cempaka Putih, dan dua gudang pusat lainnya yang berada di Cakung dan Jababeka. Kegiatan wawancara dilakukan dengan empat narasumber, yaitu kapala departemen gudang, admin gudang Jababeka (pusat), kepala gudang Cakung, Sales Support Asst Manager, dan Product Development Manager. Informasi yang didapat dari hasil wawancara, yaitu sebagai berikut:

1) Alur supply chain pada perusahaan.

2) Permasalahan yang dihadapi perusahaan mengenai pemasok.

3) Kriteria pemasok yang dibutuhkan oleh perusahaan.

4) Subkriteria pemasok yang dibutuhkan oleh perusahaan.

5) Alternatif pemasok yang selama ini digunakan oleh perusahaan.

6) Proses pemilihan pemasok secara aktual.

Penyebaran kuesioner diberikan kepada responden yang memiliki tingkat pemahaman terhadap permasalahan yang terjadi. Oleh karena itu, kuesioner diberikan kepada Assistant Manager Sales Support dan Product Development Manager. Isi kuesioner tersebut memuat tentang perbandingan berpasangan antara satu kriteria dengan kriteria yang lain, suatu sub kriteria terhadap sub kriteria lain hingga suatu alternatif terhadap alternatif lain. 


\section{Pengolahan Data}

Data yang terkumpul diolah dengan menggunakan Analytic Hierarchy Process (AHP). Metode ini digunakan untuk mengolah data kualitatif menjadi data kuantitatif dan digunakan untuk pengambilan keputusan pemilihan pemasok. Langkah-langkah pada penggunaan metode AHP adalah sebagai berikut [10]:

1) Masalah didefinisikan, solusi ditentukan, dan hierarki disusun sesuai dengan permasalahannya.

2) Prioritas elemen ditentukan, yaitu mengisi perbandingan berpasangan dengan memilih intensitas kepentingan pada kuesioner berdasarkan keterangan Pada Tabel 2.

Tabel 2. Nilai Perbandingan Berpasangan

\begin{tabular}{cl}
\hline $\begin{array}{c}\text { Intensitas } \\
\text { Kepentingan }\end{array}$ & \multicolumn{1}{c}{ Keterangan } \\
\hline 1 & $\begin{array}{l}\text { Kedua elemen sama pentingnya } \\
\text { Elemen yang satu sedikit lebih } \\
\text { penting daripada elemen yang } \\
\text { lainnya } \\
\text { Elemen yang satu lebih penting } \\
\text { daripada elemen lainnya } \\
5\end{array}$ \\
$\begin{array}{l}\text { Satu elemen jelas lebih mutlak } \\
\text { penting daripada elemen lainya }\end{array}$ \\
$\begin{array}{l}\text { Satu elemen mutlak penting } \\
\text { daripada elemen lainnya }\end{array}$ \\
$\begin{array}{l}\text { Nilai-nilai antara dua nilai } \\
\text { pertimbangan yang berdekatan } \\
\text { Jika aktifitas i merupakan satu } \\
\text { angka dibandingkan dengan } \\
\text { aktifitas j, maka j memiliki nilai } \\
\text { kebalikannya dengan i }\end{array}$ \\
\hline Kebalikan
\end{tabular}

(Sumber: Handayani dkk., 2017)

3) Sintesis, pertimbangan perbandingan berpasangan dilakukan sintesis guna memperoleh prioritas secara menyeluruh dengan melakukan penjumlahan nilai tiap kolom, selanjutnya bagi nilai tiap kolom dengan total kolom memperoleh normalisasi matriks, dan menjumlahkan nilai-nilai dari setiap baris dan membaginya dengan jumlah elemen untuk mendapatkan nilai rata-rata.

4) Pengukuran konsistensi: tiap nilai di setiap kolom dikalikan dengan prioritas relatif elemen, dijumlahkan, lalu dibagi dengan elemen prioritas relatif, maka didapatkan hasil $\lambda 1, \lambda 2$, dst.

5) $\lambda 1, \lambda 2$, dst dijumlahkan, lalu dibagi dengan banyaknya elemen guna mendapatkan $\lambda$ maks.

6) Indeks Konsistensi/ Consistency Index (CI) dihitung dengan rumus:

$C I=\frac{(\lambda m a k s-n)}{n-1}$

Keterangan:

$\mathrm{n}$ = Banyaknya elemen
7) Rasio Konsistensi/Consistency Ratio (CR) dihitung dengan rumus:

$C R=\frac{C I}{I R}$

Keterangan:

CI : Indeks Konsistensi

IR : Indeks Konsistensi Acak

CR: Rasio Konsistensi

Tabel 3. merupakan indeks konsistensi acak yang yang dapat digunakan pada rumus 2 . berdasarkan ukuran matriks.

Tabel 3. Indeks Konsistensi Acak (IR)

\begin{tabular}{cc}
$\begin{array}{c}\text { Ukuran } \\
\text { Matriks }\end{array}$ & $\begin{array}{c}\text { Nilai Indeks Konsistensi } \\
\text { Acak }\end{array}$ \\
\hline 1 & 0 \\
2 & 0 \\
3 & 0,58 \\
4 & 0,9 \\
5 & 1,12 \\
6 & 1,24 \\
7 & 1,32 \\
8 & 1,41 \\
9 & 1,45 \\
10 & 1,49 \\
11 & 1,51 \\
12 & 1,48 \\
13 & 1,56 \\
14 & 1,57 \\
15 & 1,57 \\
\hline
\end{tabular}

(Sumber: Handayani dkk., 2017)

8) Melakukan pemeriksaan konsistensi hirarki dengan menggunakan nilai CR. Nilai CR harus lebih kecil dari 0,1 atau tidak lebih dari $10 \%$. Jika nilai CR lebih kecil dari $0,1(10 \%)$ atau sama dengan $0,1(10 \%)$, maka hasil perhitungan dinyatakan benar atau konsisten.

\section{HASIL DAN PEMBAHASAN}

Penerapan metodologi yang diusulkan dilakukan pada studi pemilihan pemasok produk lampu jenis in-lite menggunakan teknik AHP untuk mengevaluasi dan memilih salah satu dari tiga pemasok yang ada, yaitu pemasok A, pemasok B, dan pemasok C. Studi dilakukan pada sebuah perusahaan prinsipal alat penerangan yang terdapat di Jakarta . Oleh karena itu, hasil dari studi ini diharapkan dapat memberikan masukkan berupa keputusan mengenai pemasok yang paling tepat bagi perusahaan agar keberlangsungan penjualan produk dapat berjalan efektif dan efisien. Teknik AHP dilakukan sesuai dengan tahapan prosedur dengan penjelasan sebagai berikut: 


\section{Penyusunan Hirarki}

Berdasarkan permasalahan yang telah dijabarkan, langkah pertama yang harus dilakukan adalah menyusun struktur hirarki pemilihan pemasok untuk produk lampu jenis in-Lite. Penyusunan struktur hirarki ini merupakan langkah awal yang dilakukan dalam metode Analitycal Hierarchy Process (AHP). Penyusunan struktur hirarki pemilihan pemasok terdiri dari empat tingkatan, yaitu :

1) Tujuan, melakukan pemilihan pemasok dari kriteria dan subkriteria yang ditetapkan divisi Sales Support sebagai sasaran utama yang ingin dicapai perusahaan.

2) Kriteria, melakukan evaluasi pemasok untuk produk lampu jenis in-Lite. Kriteria dihasilkan berdasarkan wawancara dengan Sales Support Asst Manager yang telah didelegasikan oleh Product Development Manager. Hasil wawancara didapatkan kriteria baru yang ditetapkan perusahaan, yaitu produksi, harga, pengiriman, kualitas, pelayanan, ketepatan produk, dan pemilihan tempat.

3) Subkriteria, membuat sub kriteria dari kriteria yang telah ditentukan sebagai penilaian lebih lanjut untuk pemilihan pemasok seperti yang terdapat pada Tabel 4.

4) Alternatif Solusi

Alternatif solusi merupakan tingkatan terakhir dalam pemilihan pemasok. Ada tiga alternatif solusi dalam menangani masalah pemilihan pemasok untuk produk lampu in-Lite, yaitu: Pemasok A, B, dan C.
Tabel 4. Kriteria dan Subkriteria Pemilihan Pemasok

\begin{tabular}{|c|c|c|}
\hline No. & Kriteria & Subkriteria \\
\hline 1. & Produksi & \\
\hline 2. & Harga & - Proses pembayaran \\
\hline & & $\begin{array}{l}\text { Harga sesuai dengan } \\
\text { kualitas }\end{array}$ \\
\hline 3. & Pengiriman & $\begin{array}{l}\text { Biaya pengiriman } \\
\text { Lead time }\end{array}$ \\
\hline 4. & Kualitas & $\begin{array}{l}\text { Kesesuaian kualitas produk } \\
\text { yang telah ditetapkan } \\
\text { Kemampuan memberikan } \\
\text { produk yang tidak cacat }\end{array}$ \\
\hline 5. & Pelayanan & $\begin{array}{l}\text { Respon saat penerimaan } \\
\text { order } \\
\text { - Respon saat terjadi claim } \\
\text { - Garansi }\end{array}$ \\
\hline 6. & Ketepatan & Ketepatan jumlah produk \\
\hline & Produk & $\begin{array}{l}\text { Ketepatan isi dengan } \\
\text { kemasan }\end{array}$ \\
\hline 7. & $\begin{array}{l}\text { Pemilihan } \\
\text { Tempat }\end{array}$ & \\
\hline
\end{tabular}

\section{Penyusunan Prioritas Elemen}

Penyusunan prioritas elemen ini berdasarkan hasil kuesioner yang telah diisi oleh Sales Support Assistant Manager dan Product Development Manager selaku pihak yang berkaitan dalam proses pemilihan pemasok sebelumnya. Hasil penyusunan prioritas elemen dari masing-masing kriteria dan subkriteria dengan melakukan perhitungan sesuai dengan tahapan proses, yaitu langkah-langkah pada penggunaan AHP [10]. Hasil perhitungan matriks perbandingan berpasangan terdapat pada Tabel. 5 dengan menggunakan rumus geometrik.

Tabel 5. Nilai Perbandingan Berpasangan

\begin{tabular}{|c|c|c|c|c|c|c|c|}
\hline \multicolumn{8}{|c|}{ Nilai dalam desimal } \\
\hline Kriteria & Harga & Produksi & Pelayanan & Delivery & $\begin{array}{c}\text { Pemilihan } \\
\text { Tempat }\end{array}$ & Kualitas & $\begin{array}{c}\text { Ketepatan } \\
\text { Produk }\end{array}$ \\
\hline Harga & 1,00 & 7,00 & 7,00 & 7,00 & 7,00 & 0,71 & 5,92 \\
\hline Produksi & 0,14 & 1,00 & 1,29 & 1,53 & 1,41 & 0,14 & 0,88 \\
\hline Pelayanan & 0,14 & 0,77 & 1,00 & 1,22 & 5,92 & 0,17 & 1,18 \\
\hline Delivery & 0,14 & 0,65 & 0,82 & 1,00 & 2,65 & 0,15 & 0,41 \\
\hline Pemilihan Tempat & 0,14 & 0,71 & 0,17 & 0,38 & 1,00 & 0,15 & 0,15 \\
\hline Kualitas & 1,41 & 7,00 & 5,92 & 6,48 & 6,48 & 1,00 & 1,00 \\
\hline Ketepatan Produk & 0,17 & 1,13 & 0,85 & 2,45 & 6,48 & 1,00 & 1,00 \\
\hline Jumlah & 3,15 & 18,27 & 17,04 & 20,06 & 30,94 & 3,33 & 10,54 \\
\hline
\end{tabular}

Nilai perbandingan berpasangan yang didapatkan akan digunakan untuk mencari sintesis dengan menghitung nilai bobot atau priority weight guna mendapatkan nilai prioritas bobot pada masing-masing kriteria yang terdapat pada Tabel 6. 
Tabel 6. Nilai Prioritas Bobot Kriteria

\begin{tabular}{lcccccccccc}
\hline \multicolumn{1}{c}{ Kriteria } & Harga & $\begin{array}{c}\text { Produk- } \\
\text { si }\end{array}$ & $\begin{array}{c}\text { Pelaya- } \\
\text { nan }\end{array}$ & Delivery & $\begin{array}{c}\text { Pemilihan } \\
\text { Tempat }\end{array}$ & Kualitas & $\begin{array}{c}\text { Ketepatan } \\
\text { Produk }\end{array}$ & Jumlah & $\begin{array}{c}\text { Bobot } \\
\text { Priori- } \\
\text { tas }\end{array}$ \\
\hline Harga & 0,32 & 0,38 & 0,41 & 0,35 & 0,23 & 0,21 & 0,56 & 2,46 & 0,3514 & 1 \\
Produksi & 0,05 & 0,05 & 0,08 & 0,08 & 0,05 & 0,04 & 0,08 & 0,42 & 0,0606 & 5 \\
Pelayanan & 0,05 & 0,04 & 0,06 & 0,06 & 0,19 & 0,05 & 0,11 & 0,56 & 0,0802 & 4 \\
Delivery & 0,05 & 0,04 & 0,05 & 0,05 & 0,09 & 0,05 & 0,04 & 0,35 & 0,0499 & 6 \\
Pemilihan Tempat & 0,05 & 0,04 & 0,01 & 0,02 & 0,03 & 0,05 & 0,01 & 0,21 & 0,0294 & 7 \\
Kualitas & 0,45 & 0,38 & 0,35 & 0,32 & 0,21 & 0,30 & 0,09 & 2,11 & 0,3009 & 2 \\
Ketepatan Produk & 0,05 & 0,06 & 0,05 & 0,12 & 0,21 & 0,30 & 0,09 & 0,89 & 0,1275 & 3 \\
\hline & \multicolumn{10}{c}{ Jumlah } \\
\hline
\end{tabular}

Dari Tabel 7. nilai eigen value ( $\lambda$ max) didapatkan dengan menjumlahkan $\lambda 1$ sampai dengan $\lambda 7$. Nilai CI didapatkan sebesar 0.1219 menggunakan rumus (1) dan nilai CR didapatkan sebesar 0.0924 dengan menggunakan rumus (2). Hasil CR menunjukkan bahwa hasil perhitungan CR lebih kecil dari 0,1 atau $10 \%$. Hal ini sesuai dengan nilai rata-rata indeks konsistensi acak
Saaty yang banyak digunakan pada penelitian sebelumnya dengan nilai CR yang dihasilkan lebih kecil dari 0,1 (10\%) atau sama dengan 0,1 (10\%), maka hasil perhitungan tersebut dapat dinyatakan benar atau konsisten [2, 8, 9, 11-13, 16].

Tabel 7. Nilai Vektor Jumlah Tertimbang

\begin{tabular}{lccccccccc}
\hline \multicolumn{1}{c}{ Kriteria } & Harga & $\begin{array}{c}\text { Produk- } \\
\text { si }\end{array}$ & $\begin{array}{c}\text { Pelaya- } \\
\text { nan }\end{array}$ & $\begin{array}{c}\text { Pengirim- } \\
\text { an }\end{array}$ & $\begin{array}{c}\text { Pemilihan } \\
\text { Tempat }\end{array}$ & $\begin{array}{c}\text { Kuali- } \\
\text { tas }\end{array}$ & $\begin{array}{c}\text { Ketepa- } \\
\text { tan } \\
\text { Produk }\end{array}$ & $\begin{array}{c}\text { Vektor } \\
\text { Bobot }\end{array}$ & $\begin{array}{c}\text { Jumlah } \\
\text { Tertimbang }\end{array}$ \\
\hline Harga & 1,00 & 7,00 & 7,00 & 7,00 & 7,00 & 0,71 & 5,92 & 0,3514 & 2,859 \\
Produksi & 0,14 & 1,00 & 1,29 & 1,53 & 1,41 & 0,14 & 0,88 & 0,0606 & 0,487 \\
Pelayanan & 0,14 & 0,77 & 1,00 & 1,22 & 5,92 & 0,17 & 1,18 & 0,0802 & 0,614 \\
Pengiriman & 0,14 & 0,65 & 0,82 & 1,00 & 2,65 & 0,15 & 0,41 & 0,0499 & 0,381 \\
Pemilihan Tempat & 0,14 & 0,71 & 0,17 & 0,38 & 1,00 & 0,15 & 0,15 & 0,0294 & 0,221 \\
Kualitas & 1,41 & 7,00 & 5,92 & 6,48 & 6,48 & 1,00 & 1,00 & 0,3009 & 2,338 \\
Ketepatan Produk & 0,17 & 1,13 & 0,85 & 2,45 & 6,48 & 1,00 & 1,00 & 0,1275 & 0,937 \\
\hline
\end{tabular}

Perhitungan vektor jumlah tertimbang seperti pada Tabel 7. akan digunakan untuk menghitung vektor konsistensi (VK) yang terdapat pada Tabel 8.

Tabel 8. Vektor Konsistensi

\begin{tabular}{cc}
\hline \multicolumn{2}{c}{ Vektor Konsistensi } \\
\hline$\lambda 1$ & 8,1381 \\
$\lambda 2$ & 8,0472 \\
$\lambda 3$ & 7,6568 \\
$\lambda 4$ & 7,6445 \\
$\lambda 5$ & 7,5079 \\
$\lambda 6$ & 7,7711 \\
$\lambda 7$ & 7,3548 \\
$\lambda \max$ & 7,7315 \\
$C I$ & 0,1219 \\
$C R$ & 0,0924 \\
\hline
\end{tabular}

\section{Pemilihan Alternatif Berdasarkan Kriteria}

Hasil perhitungan pada pengolahan data dilakukan rekapitulasi dan analisis prioritas global guna mendapatkan pemilihan alternatif berdasarkan kriteria dan subkriteria yang telah ditetapkan. Berikut hasil rekapitulasi perhitungan dan analisis prioritas global pada pemilihan alternatif pemasok:
1) Hasil rekapitulasi bobot keseluruhan

Hasil rekapitulasi bobot keseluruhan ini menampilkan hasil bobot prioritas yang telah dilakukan perhitungan perbandingan berpasangan pada setiap level kriteria.

Tabel 9. Rekapitulasi Bobot Keseluruhan

\begin{tabular}{lccc}
\hline \multicolumn{1}{c}{ Kriteria } & $\begin{array}{r}\text { Priority } \\
\text { Weight }\end{array}$ & \% & Prioritas \\
\hline Produksi & 0,0606 & $6 \%$ & 5 \\
Harga & 0,3514 & $35 \%$ & 1 \\
Pengiriman & 0,0499 & $5 \%$ & 6 \\
Kualitas & 0,3009 & $30 \%$ & 2 \\
Pelayanan & 0,0802 & $8 \%$ & 4 \\
Ketepatan Produk & 0,1275 & $13 \%$ & 3 \\
Pemilihan Tempat & 0,0294 & $3 \%$ & 7 \\
\hline
\end{tabular}

Berdasarkan hasil rekap bobot prioritas kriteria pada Tabel 9. diketahui bahwa kriteria harga merupakan prioritas utama bagi perusahaan, dilanjut dengankriteria kualitas, ketepatan produk, pelayanan, produksi, delivery, dan pemilihan tempat. 
2) Hasil rekap Bobot Prioritas pada Sub Kriteria

Berdasarkan hasil rekap bobot prioritas pada sub kriteria yang terdapat pada Tabel 10. diketahui bahwa kriteria harga menjadi prioritas utama perusahaan, yaitu pada subkriteria kesesuaian harga dengan kualitas yang sesuai.

Tabel 10. Bobot Prioritas pada Subkriteria

\begin{tabular}{lcccc}
\hline \multirow{2}{*}{ Kriteria } & $\begin{array}{c}\text { Sub } \\
\text { Kriteria }\end{array}$ & $\begin{array}{c}\text { Priority } \\
\text { Weight }\end{array}$ & $\%$ & Prioritas \\
\hline \multirow{2}{*}{ Harga } & $\mathrm{H} 1$ & 0,1179 & $12 \%$ & 2 \\
\cline { 2 - 5 } & $\mathrm{H} 2$ & 0,8821 & $88 \%$ & 1 \\
\hline \multirow{2}{*}{ Kualitas } & $\mathrm{K} 1$ & 0,5000 & $50 \%$ & 1 \\
\cline { 2 - 5 } $\begin{array}{l}\text { Ketetapan } \\
\text { Produk }\end{array}$ & $\mathrm{KP} 1$ & 0,5000 & $50 \%$ & 2 \\
\cline { 2 - 5 } & $\mathrm{KP} 2$ & 0,2612 & $26 \%$ & 2 \\
\hline \multirow{3}{*}{ Pelayanan } & $\mathrm{P} 1$ & 0,4415 & $44 \%$ & 2 \\
\cline { 2 - 5 } & $\mathrm{P} 2$ & 0,0624 & $6 \%$ & 3 \\
\hline \multirow{2}{*}{ Pengiriman } & $\mathrm{P} 3$ & 0,4961 & $50 \%$ & 1 \\
\cline { 2 - 5 } & $\mathrm{D} 1$ & 0,1179 & $12 \%$ & 2 \\
\hline $\begin{array}{l}\text { Pemilihan } \\
\text { Tempat }\end{array}$ & - & 0,8821 & $88 \%$ & 1 \\
\hline Produksi & - & - & - & - \\
\hline
\end{tabular}

3) Hasil rekap Bobot Prioritas Alternatif

Tabel 11. Menunjukkan hasil perhitungan bobot prioritas pemasok pada tiap masing-masing kriteria. Secara umum diketahui bobot prioritas masingmasing pada Pemasok A, Pemasok B, dan Pemasok C. Kriteria dari masing-masing alternatif pemasok diberikan rangking sesuai dengan bobotnya. Berdasarkan hasil di atas didapatkan rangking dari ketiga pemasok, secara umum bobot tertinggi dan memiliki prioritas pertama terdapat pada Pemasok A dengan kriteria: harga, kualitas, ketepatan jumlah, pelayanan, dan pemilihan tempat.

Tabel 11. Bobot Prioritas Alternatif

\begin{tabular}{|c|c|c|c|}
\hline Kriteria & Alternatif & Bobot & Prioritas \\
\hline \multirow{3}{*}{ Harga } & Pemasok A & 0,1919 & 1 \\
\hline & Pemasok B & 0,0870 & 2 \\
\hline & Pemasok C & 0,0301 & 3 \\
\hline \multirow{3}{*}{ Kualitas } & Pemasok A & 0,1352 & 1 \\
\hline & Pemasok B & 0,1352 & 2 \\
\hline & Pemasok C & 0,0451 & 3 \\
\hline \multirow{3}{*}{$\begin{array}{l}\text { Ketepatan } \\
\text { Jumlah }\end{array}$} & Pemasok A & 0,0433 & 1 \\
\hline & Pemasok B & 0,0433 & 2 \\
\hline & Pemasok C & 0,0433 & 3 \\
\hline \multirow{3}{*}{ Palayanan } & Pemasok A & 0,0184 & 1 \\
\hline & Pemasok B & 0,0179 & 2 \\
\hline & Pemasok C & 0,0172 & 3 \\
\hline \multirow{3}{*}{ Pengiriman } & Pemasok A & 0,0103 & 3 \\
\hline & Pemasok B & 0,0224 & 1 \\
\hline & Pemasok C & 0,0191 & 2 \\
\hline \multirow{3}{*}{$\begin{array}{c}\text { Pemilihan } \\
\text { Tempat }\end{array}$} & Pemasok A & 0,0265 & 1 \\
\hline & Pemasok B & 0,0120 & 2 \\
\hline & Pemasok C & 0,0092 & 3 \\
\hline \multirow{3}{*}{ Produksi } & Pemasok A & 0,0170 & 2 \\
\hline & Pemasok B & 0,0623 & 1 \\
\hline & Pemasok C & 0,0136 & 3 \\
\hline
\end{tabular}

Tabel 12. Perhitungan Bobot Subkriteria Keseluruhan

\begin{tabular}{|c|c|c|c|c|}
\hline Level 1 (Kriteria) & $\begin{array}{l}\text { Priority Weight } \\
\text { Level } 1\end{array}$ & Level 2 (Sub Kriteria) & $\begin{array}{l}\text { Priority Weight } \\
\text { Level } 2\end{array}$ & $\begin{array}{l}\text { Bobot Sub Kriteria } \\
\text { Keseluruhan }\end{array}$ \\
\hline \multirow{2}{*}{ Harga } & \multirow{2}{*}{0,3089} & Cara Pembayaran & 0,1179 & 0,0364 \\
\hline & & Kesesuaian harga dengan kualitas & 0,8821 & 0,2725 \\
\hline \multirow{2}{*}{ Kualitas } & \multirow{2}{*}{0,3154} & $\begin{array}{l}\text { Kesesuaian kualitas produk yang } \\
\text { telah ditetapkan }\end{array}$ & 0,5000 & 0,1577 \\
\hline & & $\begin{array}{l}\text { Kemampuan memberikan kualitas } \\
\text { yang konsisten }\end{array}$ & 0,5000 & 0,1577 \\
\hline \multirow{2}{*}{ Ketepatan Produk } & \multirow{2}{*}{0,1300} & Ketepatan jumlah barang & 0,7388 & 0,0960 \\
\hline & & Ketepatan isi kemasan & 0,2612 & 0,0340 \\
\hline \multirow{3}{*}{ Pelayanan } & \multirow{3}{*}{0,0534} & Respon saat penerimaan order & 0,4415 & 0,0236 \\
\hline & & Respon saat claim barang & 0,0624 & 0,0033 \\
\hline & & Garansi & 0,4961 & 0,0265 \\
\hline \multirow[b]{2}{*}{ Delivery } & \multirow[b]{2}{*}{0,0518} & Ongkos pengiriman & 0,1179 & 0,0061 \\
\hline & & $\begin{array}{l}\text { Lead time antara pemesanan dan } \\
\text { pengiriman }\end{array}$ & 0,8821 & 0,0457 \\
\hline Pemilihan Tempat & 0,0476 & - & 0,0000 & 0,0476 \\
\hline Produksi & 0,0929 & - & 0,0000 & 0,0929 \\
\hline Total Bobot & 1,0000 & & & 1,0000 \\
\hline
\end{tabular}

Tabel 13. Perhitungan Bobot Alternatif Secara Keseluruhan 


\begin{tabular}{|c|c|c|c|c|c|}
\hline Level 1 (Kriteria) & $\begin{array}{l}\text { Level } 2 \\
\text { (Sub Kriteria) }\end{array}$ & $\begin{array}{l}\text { Level 3 } \\
\text { (Alternatif) }\end{array}$ & $\begin{array}{l}\text { Priority Weight } \\
\text { Level } 3\end{array}$ & $\begin{array}{l}\text { Prioritas Sub } \\
\text { Kriteria }\end{array}$ & $\begin{array}{l}\text { Prioritas } \\
\text { Keseluruhan }\end{array}$ \\
\hline \multirow{6}{*}{ Harga } & \multirow{3}{*}{ H1 } & Pemasok A & 0,6210 & \multirow{3}{*}{0,0364} & 0,0226 \\
\hline & & Pemasok B & 0,2815 & & 0,0103 \\
\hline & & Pemasok C & 0,0975 & & 0,0035 \\
\hline & \multirow{3}{*}{$\mathrm{H} 2$} & Pemasok A & 0,6210 & \multirow{3}{*}{0,2725} & 0,1692 \\
\hline & & Pemasok B & 0,2815 & & 0,0767 \\
\hline & & Pemasok C & 0,0975 & & 0,0266 \\
\hline \multirow{6}{*}{ Kualitas } & \multirow{3}{*}{ K1 } & Pemasok A & 0,4286 & \multirow{3}{*}{0,1577} & 0,0676 \\
\hline & & Pemasok B & 0,4286 & & 0,0676 \\
\hline & & Pemasok C & 0,1429 & & 0,0225 \\
\hline & \multirow{3}{*}{ K2 } & Pemasok A & 0,4286 & \multirow{3}{*}{0,1577} & 0,0676 \\
\hline & & Pemasok B & 0,4286 & & 0,0676 \\
\hline & & Pemasok C & 0,1429 & & 0,0225 \\
\hline \multirow{6}{*}{ Ketepatan Produk } & \multirow{3}{*}{ KP1 } & Pemasok A & 0,3333 & \multirow{3}{*}{0,0960} & 0,0320 \\
\hline & & Pemasok B & 0,3333 & & 0,0320 \\
\hline & & Pemasok C & 0,3333 & & 0,0320 \\
\hline & \multirow{3}{*}{ KP2 } & Pemasok A & 0,3333 & \multirow{3}{*}{0,0340} & 0,0113 \\
\hline & & Pemasok B & 0,3333 & & 0,0113 \\
\hline & & Pemasok C & 0,3333 & & 0,0113 \\
\hline \multirow{6}{*}{ Palayanan } & \multirow{3}{*}{$\mathrm{P} 1$} & Pemasok A & 0,3333 & \multirow{3}{*}{0,0236} & 0,0079 \\
\hline & & Pemasok B & 0,3333 & & 0,0079 \\
\hline & & Pemasok C & 0,3333 & & 0,0079 \\
\hline & \multirow{3}{*}{$\mathrm{P} 2$} & Pemasok A & 0,5057 & \multirow{3}{*}{0,0033} & 0,0017 \\
\hline & & Pemasok B & 0,3523 & & 0,0012 \\
\hline & & Pemasok C & 0,1420 & & 0,0005 \\
\hline \multirow{3}{*}{ Pelayanan } & \multirow{3}{*}{$\mathrm{P} 3$} & Pemasok A & 0,3333 & \multirow{3}{*}{0,0265} & 0,0088 \\
\hline & & Pemasok B & 0,3333 & & 0,0088 \\
\hline & & Pemasok C & 0,3333 & & 0,0088 \\
\hline \multirow{6}{*}{ Delivery } & \multirow{3}{*}{ D1 } & Pemasok A & 0,3333 & \multirow{3}{*}{0,0061} & 0,0020 \\
\hline & & Pemasok B & 0,3333 & & 0,0020 \\
\hline & & Pemasok C & 0,3333 & & 0,0020 \\
\hline & & Pemasok A & 0,1804 & & 0,0082 \\
\hline & D2 & Pemasok B & 0,4466 & 0,0457 & 0,0204 \\
\hline & & Pemasok C & 0,3729 & & 0,0170 \\
\hline & & Pemasok A & 0,5557 & & 0,0265 \\
\hline Pemilihan & Tempat & Pemasok B & 0,2514 & 0,0476 & 0,0120 \\
\hline & & Pemasok C & 0,1929 & & 0,0092 \\
\hline & & Pemasok A & 0,1827 & & 0,0170 \\
\hline Prodi & & Pemasok B & 0,6710 & 0,0929 & 0,0623 \\
\hline & & Pemasok C & 0,1463 & & 0,0136 \\
\hline & & otal & & 1 & 1,0000 \\
\hline
\end{tabular}

Berdasarkan hasil perhitungan pada Tabel 12. didapatkan hasil bobot alternatif keseluruhan. Perhitungan ini didapat dengan cara melakukan perkalian antara bobot keseluruhan sub kriteria yang telah dihitung dengan hasil bobot sub kriteria. Selanjutnya, akan di akumulasikan hasil bobot per alternatif untuk mendapatkan prioritas utama pemasok yang akan digunakan.

Berdasarkan akumulasi yang telah dilakukan pada Tabel 13. diketahui bahwa Pemasok A merupakan alternatif tertinggi dengan nilai bobot 0,442 dibandingkan dengan dua Pemasok lainnya. Oleh karena itu, Pemasok A merupakan pemasok yang terpilih untuk produk lampu jenis in-Lite pada PT X. Berdasarkan wawancara yang telah dilakukan diketahui bahwa sebelum menggunakan metode AHP ini, perusahaan memilih Pemasok $\mathrm{C}$ dalam menjual produknya karena pada saat itu kebutuhan perusahaan di bawah minimal order quantity Pemasok A, sehingga perusahaan tidak bisa melakukan pemesanan kembali kepada Pemasok A. Namun setelah berganti ke Pemasok $\mathrm{C}$ perusahaan masih mengalami hambatan 
dalam kontinuitas penjualan lampu jenis in-Lite. Maka dapat disimpulkan bahwa Pemasok A merupakan pemasok yang lebih baik dibandingkan pemasok lainnya.

Tabel 14. Hasil Bobot Total Tiap Alternatif

\begin{tabular}{cccc}
\hline Alternatif & $\begin{array}{c}\text { Prioritas } \\
\text { Keseluruhan }\end{array}$ & $\%$ & Prioritas \\
\hline Pemasok A & 0,442 & $44 \%$ & 1 \\
Pemasok B & 0,380 & $38 \%$ & 2 \\
Pemasok C & 0,178 & $18 \%$ & 3 \\
\hline Total & 1,000 & $100 \%$ & \\
\hline
\end{tabular}

\section{Analisis}

Hasil pengolahan data dan pembahasan di atas menunjukkan bahwa Pemasok A memiliki nilai bobot tertinggi dengan prioritas pertama pada kriteria harga, kualitas, ketepatan jumlah, pelayanan, dan pemilihan tempat, prioritas kedua pada kriteria produksi, prioritas ketiga pada kriteria delivery. Berdasarkan hasil tersebut, Pemasok A merupakan pemasok terpilih karena hasil perhitungan nilai keseluruhan dari masing-masing alternatif didapat bahwa nilai bobot tertinggi yaitu jatuh kepada Pemasok A dengan bobot sebesar 44\% dibandingkan dengan pemasok lainnya. Oleh karena itu, Pemasok A dapat dijadikan sebagai rekomendasi pemasok pada produk lampu jenis in-Lite pada PT X agar kontinuitas penjualan produk tersebut dapat berjalan dengan baik dan lancar. Hasil analisis juga menunjukkan bahwa bahwa AHP mampu memberikan jalan keluar dalam pemilihan pemasok terbaik pada produk lampu jenis in-Lite. Hal ini sesuai dengan penelitian sejenis sebelumnya yang membahas tentang pemilihan pemasok terbaik yang terdapat pada berbagai industri $[2,8,12$, $16]$.

\section{KESIMPULAN}

Matriks perbandingan berpasangan pada kriteria dan subkriteria yang telah dihitung untuk pemilihan pemasok dinyatakan telah konsisten karena memiliki nilai CR sebesar 0,0924 atau lebih kecil dari 0,1. Hasil perhitungan AHP berdasarkan kriteria dan subkriteria tersebut menyatakan bahwa Pemasok A dipilih sebagai pemasok utama untuk produk lampu jenis in-Lite dengan bobot yang didapatkan sebesar $44 \%$, sedangkan pada pemasok lainnya, sebesar 38\% untuk Pemasok B, dan $18 \%$ untuk Pemasok C. Pada studi ini metode AHP sangat membantu dalam mengambil keputusan dalam pemilihan pemasok pada produk lampu jenis in-Lite. Namun, perhitungan dapat dilakukan menggunakan metode Multiple Criteria Decision Making (MCDM) lainnya, seperti: ELECTRE, VIKOR, PROMETHEE, WSM, MAUT, ANP, TODIM, MULTIMOORA, dan
TOPSIS guna mendapatkan perbandingan atau validasi yang lebih kuat dalam melakukan pemilihan pemasok.

\section{DAFTAR PUSTAKA}

[1] R. K. Garg, "Structural equation modeling of Esupplier selection criteria in mechanical manufacturing industries," J. Clean. Prod., vol. 311, no. May, p. 127597, 2021.

[2] T. K. Saputra, "Penentuan Kriteria Dalam Pemilihan Supplier bahan Kain Pada Industri Textile Dengan Menggunakan Metode Analytical Hierarchy Process (AHP)," Universitas Islam Indonesia, 2018.

[3] M. A. Umaindra, D. Pujotomo, and P. A. W, "Perancangan Model Pemilihan Supplier Produk Cetakan Dengan Menggunakan Grey Based Topsis (Studi Kasus : Rumah Sakit Islam Sultan Agung Semarang)," J. Tek. Ind., vol. 13, no. 2, pp. 99-108, 2018.

[4] A. Azimifard, S. H. Moosavirad, and S. Ariafar, "Selecting sustainable supplier countries for Iran 's steel industry at three levels by using AHP and TOPSIS methods," Resour. Policy, vol. 57, no. August 2018, pp. 30-44, 2018.

[5] D. Devaraj, E. Syron, and P. Donnellan, "Diversification of Gas Sources to improve Security of Supply using an integrated Multiple Criteria Decision Making Approach," Clean. Responsible Consum., vol. 3, p. 100042, 2021.

[6] M. K. Ghorabaee, "Assessment of distribution center locations using a multi - expert subjective - objective decision - making approach," Sci. Rep., pp. 1-19, 2021.

[7] H. Badri, H. Lo, H. Gupta, S. Kusi-sarpong, and J. J. H. Liou, “An integrated model for selecting suppliers on the basis of sustainability innovation," J. Clean. Prod., vol. 277, p. 123261, 2020.

[8] L. Erick, E. Gorski, E. F. R. Loures, E. A. P. Santos, and F. Deschamps, "Applying machine learning to AHP multicriteria decision making method to assets prioritization in the context of industrial maintenance 4.0.," in IFACPapersOnLine, 2019, pp. 2152-2157.

[9] A. Azadeh, S. M. Asadzadeh, and M. Tanhaeean, "A consensus-based AHP for improved assessment of resilience engineering in maintenance organizations," J. Loss Prev. Process Ind., 2017.

[10] R. I. Handayani and Y. Darmianti, "Pemilihan Supplier Bahan Baku Bangunan Dengan Metode Analytical Hierarchy Process ( AHP) Pada PT . Cipta Nuansa," J. Techno Nusa Mandiri, vol. XIV, no. 1, pp. 1-8, 2017. 
[11] S. Turk and G. Sahin, "Corrigendum to " Multicriteria decision-making in the location selection for a solar PV power plant using AHP " Measurement 129 ( 2018 )," Measurement, vol. 153, p. 107384, 2020.

[12] I. Miciuła and J. Nowakowska-Grunt, "Using the AHP method to select an energy supplier for household in Poland," in 23rd International Conference on Knowledge-Based and Intelligent Information \& Engineering System, 2019, pp. 2324-2334.

[13] A. K. A. Jawwad and I. AbuNaffa, "Applying analytical hierarchy process ( AHP) in selecting best maintenance strategies for newly established chemical fertilizers plants," J. Qual. Maint. Eng., no. September, 2021.

[14] A. Lange, L. Londero, W. Leal, R. Maria, and L. Kalil, "An analysis of the applications of Analytic Hierarchy Process ( AHP) for selection of energy e ffi ciency practices in public lighting in a sample of Brazilian cities," Energy Policy, vol. 132, no. November 2018, pp. 854-864, 2019.

[15] L. P. Ghimire and Y. Kim, "An analysis on barriers to renewable energy development in," Renew. Energy, 2018.

[16] D. Meira, I. Lopes, and C. Pires, "Selection of computerized maintenance management systems to meet organizations' needs using AHP," Procedia Manuf., vol. 51, pp. 1573-1580, 2020. 